\title{
An Investigation of the Morphometry and Localization of the Foramen Ovale and Rotundum in Asymptomatic Individuals and Patients with Trigeminal Neuralgia
}

\author{
Yadigar KASTAMONI ${ }^{1}$, Ahmet DURSUN ${ }^{1}$, Veysel Atilla AYYILDIZ², Kenan OZTURK ${ }^{1}$ \\ 'Suleyman Demirel University, School of Medicine, Department of Anatomy, Isparta, Turkey \\ ${ }^{2}$ Suleyman Demirel University, School of Medicine, Department of Radiology, Isparta, Turkey \\ Corresponding author: Kenan OZTURK kenanozt@hotmail.com
}

\section{ABSTRACT}

AIM: To compare the morphometric characteristics of the foramen ovale (FO) and foramen rotundum (FR), and their localization in the middle cranial fossa on the head and neck computed tomography images of patients with trigeminal neuralgia (TN) and asymptomatic individuals.

MATERIAL and METHODS: The FO and FR length, width, and area parameters were examined in 158 asymptomatic individuals and 19 patients with TN. Their localization in the middle cranial fossa was determined according to the sagittal (y) axis passing through the middle of the dorsum sella and connecting the foremost point and the rearmost point of the skull and the transverse (x) axis passing through the middle of this axis. In the comparison with asymptomatic individuals, data on the painful side of patients with trigeminal neuralgia were used.

RESULTS: The mean width of the FO and its distance from the transverse axis were determined to be $3.36 \pm 0.79 \mathrm{~mm}$ and $1.44 \pm$ $0.39 \mathrm{~mm}$ in asymptomatic individuals and $2.88 \pm 0.83 \mathrm{~mm}$ and $1.23 \pm 0.45 \mathrm{in}$ TN patients, respectively. These FO parameters were statistically significantly smaller in patients with TN. In asymptomatic individuals, while the mean width of the FR was determined to be $2.05 \pm 0.48 \mathrm{~mm}$, the mean length was $2.14 \pm 0.47 \mathrm{~mm}$, and its distances to the transverse axis and sagittal axis were found to be $2.65 \pm 0.35 \mathrm{~mm}$ and $1.96 \pm 0.25 \mathrm{~mm}$, respectively. In patients with TN, while the mean width of the FR was revealed to be $1.77 \pm 0.46 \mathrm{~mm}$, the mean length was $1.78 \pm 0.42 \mathrm{~mm}$, and its distances to the transverse axis and sagittal axis were found to be $2.33 \pm 0.40 \mathrm{~mm}$ and $1.87 \pm 0.16 \mathrm{~mm}$, respectively. These FR parameters were statistically significantly smaller in patients with TN.

CONCLUSION: Statistically significantly smaller dimensions of the FO and FR and their distances to the sagittal and transverse axes in patients with TN suggested that they might be among the causes of TN.

KEYWORDS: Maxillary nerve, Mandibular nerve, Pain, Foramen vesalii, Middle cranial fossa

ABBREVIATIONS: TN: Trigeminal neuralgia, FO: Foramen ovale, FR: Foramen rotundum, FV: Foramen Vesalii

\section{INTRODUCTION}

$\mathrm{T}$ Trigeminal neuralgia (TN) represents one of the causes of pain in the facial region. It may be a devastating disease that disrupts the patient's professional and social life depending on the frequency and intensity of pain paroxysms and the degree of pain control. Its exact cause is unknown despite its history of over three hundred years. Probably, that is the reason for common medical treatment failures. The most common cause of $\mathrm{TN}$ is the focal compression of the trigeminal nerve root entry zone by an artery or vein. Nevertheless, TN may also occur in the absence of vascular compression, or an asymptomatic patient may have neurovascular contact
Yadigar KASTAMONI (1) : 0000-0002-3504-5853

Ahmet DURSUN (1) : 0000-0003-4568-8761
Veysel Atilla AYYILDIZ (1) : 0000-0003-0252-9023

Kenan OZTURK (10): 0000-0002-5552-8684 
$(2,12,23)$. The prevalence of $\mathrm{TN}$ in the general population is about $3-5$ cases $/ 100,000$ individuals, and the incidence ranges from 4.5 to 28.9 cases/100,000/year, increasing with age (17).

The foramen ovale (FO) is located in the posterior part of the sphenoid greater wing. Structures such as the mandibular nerve, emissary vein, lesser superficial petrosal nerve, and accessory meningeal artery pass through it. It is one of the important foramina located in the transition zone between the extracranial and intracranial structures (8). The FO is also an important structure of the cranium anatomy, which is crucial in neurosurgery since it provides access to the trigeminal nerve (16).

The foramen rotundum (FR) is a foramen present in the greater wing of the sphenoid bone and located in the fossa cranii media, and the maxillary nerve passes through it (5). The FR is located adjacent to the nasopharynx and is often invaded by nasopharyngeal cancer and other malignant brain tumors. The FR is also very close to the pterygopalatine fossa, pterygoid canal, and palatovaginal canal, which is important in transsphenoidal sinus surgery (1).

There are studies examining the correlation between the diameters of the FO and FR and TN $(2,10)$. While some of these studies reported that the narrow diameter of the $\mathrm{FO}$ and FR might be the cause of TN (10), some studies suggested that there was no relationship between the diameter of these foramina and TN (2). Different results regarding this issue that we encountered in the literature pushed us to conduct this study. Furthermore, we planned to investigate whether there was a relationship between the localization of these foramina in the middle cranial fossa and TN.

Considering the clinical significance of the structures such as the FO and FR described above, we aimed to investigate the morphometric and morphological characteristics and localization of these structures in patients with TN and asymptomatic individuals.

\section{MATERIAL and METHODS}

The present study was conducted retrospectively on the head and neck computed tomography (CT) images of individuals without any pathology or symptoms in the head and neck region and patients with TN between 2010-2019. Approval was obtained from the Clinical Research Ethics Committee for the study. In this study, the dimensions and localizations of the FO and FR in 158 asymptomatic individuals (81 females, 77 males) aged between 20 and 92 years (mean $55.03 \pm$ 19.01) and 19 patients with TN aged between 21 and 81 years (mean $55.32 \pm 17.48$ ) were examined. It was determined that the symptoms in patients with TN were on the right side in 8 patients, on the left side in 9 patients, and bilateral in 2 patients.

Head and neck CT images were obtained from the hospital's "Picture Archiving and Communicating System" in the Radiology Department. Patients with any tumors or fractures on head and neck CT images were not included in the study.
Metabolic bone conditions that might affect bone tissue, such as osteoporosis, were not questioned in patients. CT images were obtained by a multidetector 128 slice SOMATOM Definition AS Siemens (Siemens Healthcare, Erlangen, Germany) computed tomography device using the following parameters: $120 \mathrm{kV}$, slice thickness $=1 \mathrm{~mm}$, matrix $=512 \times 512$, collimation $=128 \times 0.6$ slice increment $=0.7$ pitch $=0.8 \quad$ FOV (Field of View) (250-300). A 3D reconstruction was created from the scanned axial images using the RadiAnt DICOM Viewer 2020.2 version program. After the 3D-CT image of the cranium was obtained, the calvaria was removed by taking a transverse section passing through the upper edge of the orbit and extending parallel to the Frankfurt plane. Then, the following axes were determined by looking at the cranium from the top.

y-axis: It was considered as the sagittal axis passing through the middle of the dorsum sella and connecting the foremost point and the rearmost point of the cranium (Figure 1A, B).

$\mathbf{x}$-axis: It was considered as the axis extending from the middle of the $y$-axis in the transverse direction on the transverse plane (Figure 1A, B).

The following parameters for the morphometry of the foramina were measured using the RadiAnt DICOM Viewer 2020.2 version program.

- The FO length and width

- The FO coordinates (the distance of the center of the FO to the $x$ and $y$-axes) (Figure 1A)

- The FO area

- The FO shape

- The FR length and width

- The FR coordinates (the distance of the center of the FR to the $x$ and $y$-axes) (Figure 1B)

- The FR area

\section{Statistical Analysis}

Statistical analysis was conducted using the SPSS Inc. SPSS for Windows 20.0 program. According to side and sex, the arithmetic means and standard deviations of the parameters were determined in asymptomatic individuals and patients with TN. In pairwise comparisons, the independent samples t-test was performed for parameters with normal distribution, and the Mann-Whitney $U$ test was conducted for parameters without normal distribution.

\section{RESULTS}

When all parameters were compared by sex in asymptomatic individuals and patients with $\mathrm{TN}$, a statistically significant difference was determined between sexes in the FO and FR dimensions in asymptomatic individuals and only in the FR width in patients with TN (Table I).

In the comparisons performed between the right and left sides in asymptomatic individuals and between the painful and pain-free sides in patients with $\mathrm{TN}$, a statistically significant difference was observed between the painful and pain-free 

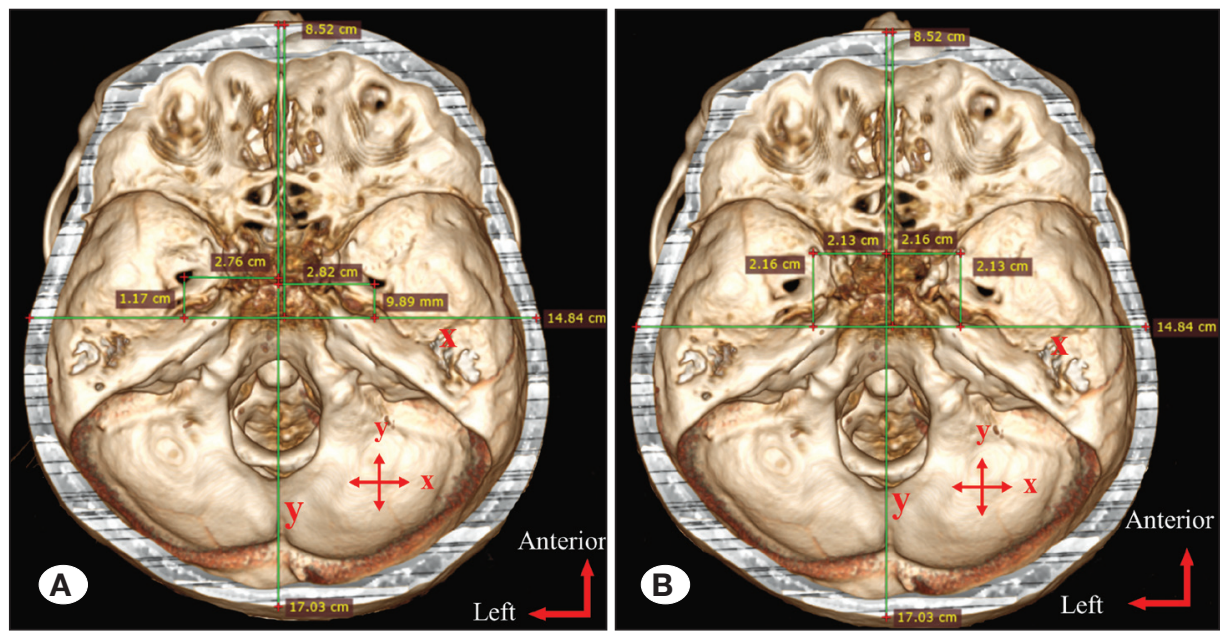

Figure 1: Distances of the foramen ovale and rotundum to the $x$ and $y$-axes.

Table I: Averages and p-values of All Parameters According to Sex in Asymptomatic Individuals and Patients with Trigeminal Neuralgia

Asymptomatic individuals

\begin{tabular}{|c|c|c|c|c|c|c|c|c|}
\hline \multicolumn{2}{|c|}{ Parameters } & \multirow{2}{*}{$\begin{array}{c}\text { Sex } \\
\text { Female }\end{array}$} & \multirow{2}{*}{$\begin{array}{c}\mathbf{n} \\
162\end{array}$} & \multirow{2}{*}{$\begin{array}{c}\begin{array}{c}\text { Mean } \\
\text { deviation }\end{array} \\
5.71 \pm 0.92\end{array}$} & \multirow{3}{*}{$\begin{array}{c}p \\
<0.001^{*}\end{array}$} & \multirow{2}{*}{$\begin{array}{c}\mathbf{n} \\
15\end{array}$} & \multirow{2}{*}{$\begin{array}{c}\begin{array}{c}\text { Mean } \pm \text { Std } \\
\text { deviation }\end{array} \\
5.22 \pm 1.49\end{array}$} & \multirow{3}{*}{$\begin{array}{c}\mathbf{p} \\
0.479\end{array}$} \\
\hline \multirow{10}{*}{ FO } & \multirow{2}{*}{ Length (mm) } & & & & & & & \\
\hline & & Male & 154 & $6.21 \pm 0.96$ & & 6 & $5.77 \pm 1.75$ & \\
\hline & \multirow{2}{*}{ Width (mm) } & Female & 162 & $3.25 \pm 0.77$ & \multirow{2}{*}{$0.009 *$} & 15 & $2.90 \pm 0.92$ & \multirow{2}{*}{0.870} \\
\hline & & Male & 154 & $3.48 \pm 0.80$ & & 6 & $2.83 \pm 0.63$ & \\
\hline & \multirow{2}{*}{ Area $\left(\mathrm{mm}^{2}\right)$} & Female & 162 & $14.29 \pm 5.54$ & \multirow{2}{*}{$<0.001^{*}$} & 15 & $13.25 \pm 7.36$ & \multirow{2}{*}{0.733} \\
\hline & & Male & 154 & $16.62 \pm 5.75$ & & 6 & $14.52 \pm 8.38$ & \\
\hline & \multirow{2}{*}{ Distance to $\mathrm{x}$-axis (cm) } & Female & 162 & $1.44 \pm 0.38$ & \multirow{2}{*}{0.826} & 15 & $1.20 \pm 0.43$ & \multirow{2}{*}{0.657} \\
\hline & & Male & 154 & $1.43 \pm 0.41$ & & 6 & $1.30 \pm 0.51$ & \\
\hline & \multirow{2}{*}{ Distance to $y$-axis $(\mathrm{cm})$} & Female & 162 & $2.56 \pm 0.18$ & \multirow{2}{*}{$<0.001^{*}$} & 15 & $2.54 \pm 0.15$ & \multirow{2}{*}{0.789} \\
\hline & & Male & 154 & $2.66 \pm 0.21$ & & 6 & $2.56 \pm 0.10$ & \\
\hline \multirow{10}{*}{ FR } & \multirow{2}{*}{ Length (mm) } & Female & 162 & $2.07 \pm 0.42$ & \multirow{2}{*}{$0.008^{*}$} & 15 & $1.86 \pm 0.45$ & \multirow{2}{*}{0.169} \\
\hline & & Male & 154 & $2.22 \pm 0.52$ & & 6 & $1.57 \pm 0.29$ & \\
\hline & \multirow{2}{*}{ Width (mm) } & Female & 162 & $1.99 \pm 0.41$ & \multirow{2}{*}{$0.028^{*}$} & 15 & $1.93 \pm 0.43$ & \multirow{2}{*}{$0.013^{\star}$} \\
\hline & & Male & 154 & $2.11 \pm 0.53$ & & 6 & $1.39 \pm 0.33$ & \\
\hline & \multirow{2}{*}{ Area $\left(\mathrm{mm}^{2}\right)$} & Female & 162 & $3.29 \pm 0.32$ & \multirow{2}{*}{0.099} & 15 & $3.13 \pm 1.46$ & \multirow{2}{*}{0.189} \\
\hline & & Male & 154 & $2.69 \pm 0.37$ & & 6 & $2.20 \pm 1.25$ & \\
\hline & \multirow{2}{*}{ Distance to $\mathrm{x}$-axis (cm) } & Female & 162 & $2.62 \pm 0.32$ & \multirow{2}{*}{0.066} & 15 & $2.30 \pm 0.40$ & 0570 \\
\hline & & Male & 154 & $2.69 \pm 0.37$ & & 6 & $2.41 \pm 0.45$ & $0.5 / 8$ \\
\hline & & Female & 162 & $1.92 \pm 0.25$ & คח ח๐:* & 15 & $1.89 \pm 0.18$ & \\
\hline & b-axis (c & Male & 154 & $1.99 \pm 0.25$ & $0.008^{\star}$ & 6 & $1.83 \pm 0.09$ & 0.4 \\
\hline
\end{tabular}

* $p<0.05$, FO: Foramen ovale, FR: Foramen rotundum. (painful side)

Trigeminal neuralgia 
sides only in the distance of patients with TN to the $y$-axis $(p=0.020)$ (Table II). Furthermore, the right and left localizations of the FO and FR in asymptomatic individuals and the localization of only the symptomatic sides in patients with TN are presented in graphs (Figure 2).

Upon examining the FO shape in asymptomatic individuals and patients with TN, we most frequently found the "oval"shaped FO in both asymptomatic individuals and patients with TN (Table III).

In the present study, we detected the foramen Vesalii (FV) in 11 of the asymptomatic individuals (on the right side in 4 of them, on the left side in 5 of them, bilaterally in 2 of them) and a second $\mathrm{FO}$ in 1 (on the right side) individual. Furthermore, we determined that 3 FOs (2 on the right side, 1 on the left side) were incomplete (seemed to be connected with the foramen lacerum), and that there was 1 (right) spiny protrusion in the foramen, and finally, 1 (left) tubercle in the foramen. In patients with TN, no foramen was observed, except for only one FO on both sides.

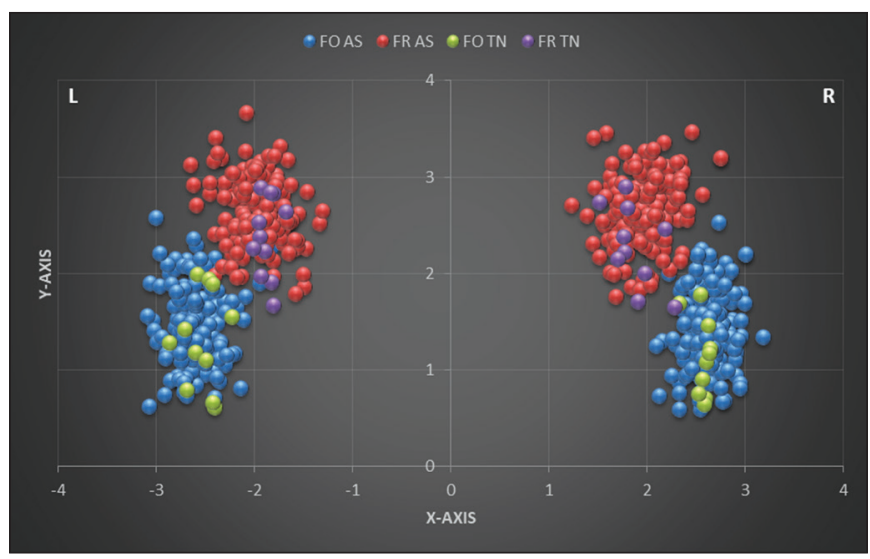

Figure 2: Distribution chart of the localizations of the foramen ovale and rotundum in asymptomatic individuals and patients with trigeminal neuralgia according to the $\mathrm{x}$ and $\mathrm{y}$-axes (R: right, L: left, FO AS: foramen ovale in asymptomatic individuals, FR AS: foramen rotundum in asymptomatic individuals, FO TN: foramen ovale in patients with trigeminal neuralgia, FR TN: foramen rotundum in patients with trigeminal neuralgia).

Table II: Averages and p-values of All Parameters According to Sides in Asymptomatic Individuals and Patients with Trigeminal Neuralgia

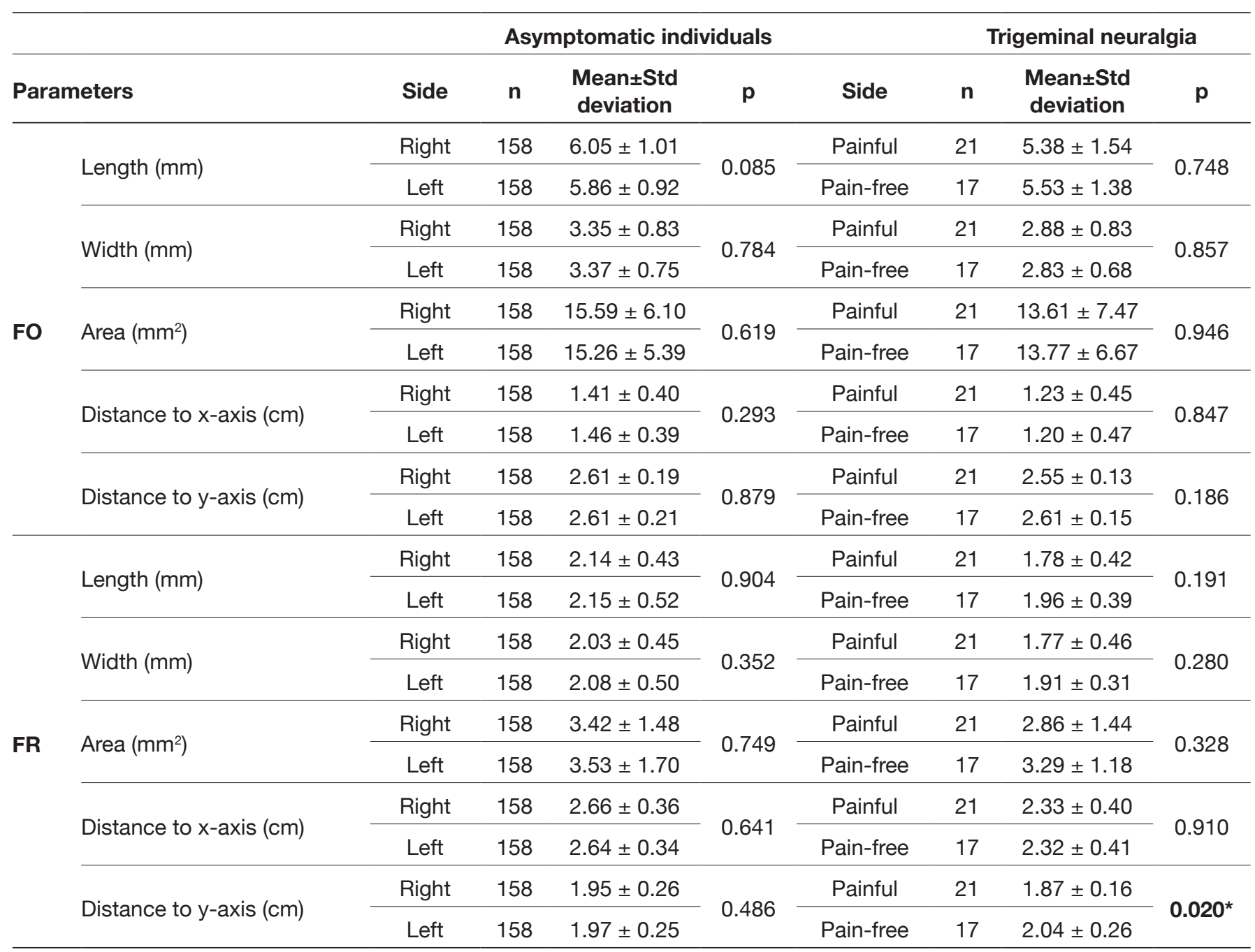

* $p<0.05$, FO: Foramen ovale, FR: Foramen rotundum. 
As a result of the comparison between the mean values of the sum of both sides in asymptomatic individuals and the mean values of the painful sides in patients with $\mathrm{TN}$, significant differences were observed in some parameters related to the dimensions and localizations of the FO and FR (Table IV).

Table III: Frequency of the Shapes of the Foramen Ovale

\begin{tabular}{lcc}
\hline $\begin{array}{l}\text { Shape of the } \\
\text { foramen ovale }\end{array}$ & $\begin{array}{c}\text { Asymptomatic } \\
\text { individuals } \\
\mathbf{n}(\%)\end{array}$ & $\begin{array}{c}\text { Trigeminal } \\
\text { neuralgia } \\
\mathbf{n}(\%)\end{array}$ \\
\hline Almond & $47(14.9)$ & $4(19)$ \\
\hline Kidney & $6(1.9)$ & - \\
\hline Oval & $256(81)$ & $17(81)$ \\
\hline Round & $7(2.2)$ & - \\
\hline Total & $316(100)$ & $21(100)$ \\
\hline
\end{tabular}

\section{DISCUSSION}

TN represents the most important disease of the trigeminal nerve. The vascular compression of the dorsal root of the trigeminal nerve by the abnormal loop of blood vessels is now considered the most common cause of $\mathrm{TN}$. It has been reported that the incidence of TN is more common in females compared to males and is twice as high on the right side compared to the left side $(11,12)$. However, there are no anatomical reasons for the folds of blood vessels to be more frequent on the right side of the cranial fossa. Moreover, vascular compression has been reported in asymptomatic patients and patients with TN without abnormal blood vessels. Therefore, the idea that the cause of TN is vascular compression alone has been excluded (12). In cases in which neurovascular compression has been excluded, it has been suggested that a narrow FO and FR may be etiologically important in patients with TN (10).

Many studies examining the FO dimensions have been conducted. Patil et al. revealed that the mean length of the FO in dry bones was $7.0 \mathrm{~mm}$ on the right side and $6.8 \mathrm{~mm}$

Table IV: Comparison of FO and FR Parameters Between the Painful Sides of Patients with Trigeminal Neuralgia and Asymptomatic Individuals

\begin{tabular}{|c|c|c|c|c|c|}
\hline \multicolumn{2}{|c|}{ Parameters } & \multirow{3}{*}{$\begin{array}{c}\text { Group } \\
\text { Asymptomatic } \\
\text { TN painful side }\end{array}$} & \multirow{3}{*}{$\begin{array}{c}\text { Number of sides } \\
316 \\
21\end{array}$} & \multirow{2}{*}{$\begin{array}{c}\text { Mean } \pm \text { Std deviation (Range) } \\
5.95 \pm 0.97(3.58-8.94)\end{array}$} & \multirow{3}{*}{$\frac{\mathbf{p}}{0.107}$} \\
\hline \multirow{10}{*}{ FO } & \multirow{2}{*}{ Length $(\mathrm{mm})$} & & & & \\
\hline & & & & $5.38 \pm 1.54(3.21-8.93)$ & \\
\hline & \multirow{2}{*}{ Width (mm) } & Asymptomatic & 316 & $3.36 \pm 0.79(2.05-6.34)$ & \multirow{2}{*}{$0.008^{*}$} \\
\hline & & TN painful side & 21 & $2.88 \pm 0.83(1.54-5.20)$ & \\
\hline & \multirow{2}{*}{ Area $\left(\mathrm{mm}^{2}\right)$} & Asymptomatic & 316 & $15.42 \pm 5.75(4.69-35.59)$ & \multirow{2}{*}{0.288} \\
\hline & & TN painful side & 21 & $13.61 \pm 7.47(4.51-29.78)$ & \\
\hline & \multirow{2}{*}{ Distance to $\mathrm{x}$-axis $(\mathrm{cm})$} & Asymptomatic & 316 & $1.44 \pm 0.39(0.60-2.58)$ & \multirow{2}{*}{$0.021^{*}$} \\
\hline & & TN painful side & 21 & $1.23 \pm 0.45(0.62-1.99)$ & \\
\hline & \multirow{2}{*}{ Distance to $y$-axis $(\mathrm{cm})$} & Asymptomatic & 316 & $2.61 \pm 0.20(1.83-3.18)$ & \multirow{2}{*}{0.165} \\
\hline & & TN painful side & 21 & $2.55 \pm 0.13(2.23-2.87)$ & \\
\hline \multirow{10}{*}{ FR } & \multirow{2}{*}{ Length (mm) } & Asymptomatic & 316 & $2.14 \pm 0.47(0.90-4.60)$ & \multirow{2}{*}{$0.001^{*}$} \\
\hline & & TN painful side & 21 & $1.78 \pm 0.42(1.19-2.86)$ & \\
\hline & \multirow{2}{*}{ Width (mm) } & Asymptomatic & 316 & $2.05 \pm 0.48(1.03-4.30)$ & \multirow{2}{*}{$0.011^{*}$} \\
\hline & & TN painful side & 21 & $1.77 \pm 0.46(1.07-2.68)$ & \\
\hline & \multirow{2}{*}{ Area $\left(\mathrm{mm}^{2}\right)$} & Asymptomatic & 316 & $3.47 \pm 1.59(0.77-13.17)$ & \multirow{2}{*}{0.088} \\
\hline & & TN painful side & 21 & $2.86 \pm 1.44(0.95-5.67)$ & \\
\hline & \multirow{2}{*}{ Distance to $\mathrm{x}$-axis $(\mathrm{cm})$} & Asymptomatic & 316 & $2.65 \pm 0.35(1.76-3.67)$ & \multirow{2}{*}{$<0.001^{*}$} \\
\hline & & TN painful side & 21 & $2.33 \pm 0.40(1.65-2.90)$ & \\
\hline & \multirow{2}{*}{ Distance to $y$-axis $(\mathrm{cm})$} & Asymptomatic & 316 & $1.96 \pm 0.25(1.23-2.75)$ & \multirow{2}{*}{$0.036^{*}$} \\
\hline & & TN painful side & 21 & $1.87 \pm 0.16(1.51-2.28)$ & \\
\hline
\end{tabular}

${ }^{*} p<0.05$, FO: Foramen ovale, FR: Foramen rotundum, TN: Trigeminal neuralgia. 
on the left side and that its width was $5.0 \mathrm{~mm}$ on the right side and $4.7 \mathrm{~mm}$ on the left side (13). In their study on dry bones, Somesh et al. (16) found that the mean length of the FO was $7.64 \mathrm{~mm}$ on the right side and $7.56 \mathrm{~mm}$ on the left side. Furthermore, they determined that the mean width was $5.12 \mathrm{~mm}$ on the right side and $5.24 \mathrm{~mm}$ on the left side and that the difference between the sides was not statistically significant. In their study on dry skulls, Gupta and Gupta reported that the FO had a mean length of 7.44 (3.58-12.97) $\mathrm{mm}$ and a mean width of $4.13(2.42-8.5) \mathrm{mm}$ (3). Somesh et al. determined that the area of the FO was $30.80 \mathrm{~mm}^{2}$ and 31.31 $\mathrm{mm}^{2}$, respectively, on the right and left sides in dry skulls (16). Our findings on the length and width parameters are similar to other studies. However, the FO area found by Somesh et al. was quite different from our results (16). In their study, unlike our study, the researchers did not measure the FO area directly and calculated it with a formula using the length and width of the FO (16). We considered that it was the reason for the difference between our results.

Similar to our study, Gupta and Gupta investigated the FO distance to the midline and reported that the FO center was located approximately $2.5 \mathrm{~cm}$ from the midline in dry bones (3). Their data on the distance to the midline correspond to the distance to the y-axis in our study. In our study, the distance to the $y$-axis was found to be $2.61 \mathrm{~cm}$ on the right and left sides in asymptomatic individuals and $2.55 \mathrm{~cm}$ on the painful side and $2.61 \mathrm{~cm}$ on the pain-free side in patients with TN. Their results are quite similar to our results. This similarity makes us think that the FO distance to the $y$-axis did not change in dry skulls, asymptomatic individuals, and patients with TN.

Patil et al. indicated that the morphometric measurements of the right and left-side FO showed an asymmetry in the South Indian population, although they were statistically insignificant (13). Furthermore, they also stated that the morphometry of the FO differed in various countries and regions, and therefore, a specific regional analysis of the FO should be performed to help clinical and surgical procedures. Similar to the findings obtained by Patil et al. (13), our research detected no significant difference between the sides in any of the FOrelated parameters.

Several anatomical and radiological studies investigating the FO dimensions in patients with TN were conducted $(4,10,11)$. In their study conducted on CT images, Hwang et al. reported that the FO had a mean length of $8.18 \pm 0.82 \mathrm{~mm}$ (on the right side: $8.11 \pm 0.97 \mathrm{~mm}$, on the left side: $8.24 \pm 0.64 \mathrm{~mm}$ ) and a mean width of $4.06 \pm 0.86 \mathrm{~mm}$ (on the right side: $4.12 \pm 0.99$ $\mathrm{mm}$, on the left side: $4.01 \pm 0.72 \mathrm{~mm}$ ) in patients with TN (4). They also found no significant difference between the right and left sides. Liu et al. (10) reported that the mean length of the FO was $7.38 \pm 1.09 \mathrm{~mm}$ on the painful side and $7.89 \pm 1.66 \mathrm{~mm}$ on the pain-free side and that the mean width of the FO was $3.62 \pm 0.47 \mathrm{~mm}$ on the painful side and $4.19 \pm 0.87 \mathrm{~mm}$ on the pain-free side on the CT images of patients with TN. They also found that the FO length and width did not differ significantly between the painful and pain-free sides. However, the width/ length ratio showed a significant difference. Therefore, Liu et al. reported that the narrow FO might be etiologically important in a small percentage of patients with TN (10). In our study, the mean length of the FO was found to be $5.38 \pm 1.54$ $\mathrm{mm}$ (painful side: $5.38 \pm 1.54 \mathrm{~mm}$, pain-free side: $5.53 \pm 1.38$ $\mathrm{mm}$ ), and the mean width of the FO was found to be $2.88 \pm$ $0.83 \mathrm{~mm}$ (painful side: $2.88 \pm 0.83 \mathrm{~mm}$, pain-free side: 2.83 $\pm 0.68 \mathrm{~mm}$ ) in patients with TN. The findings of our research were slightly different from the two studies mentioned above. We considered that this difference was caused by the fact that the study conducted by Hwang et al. on Korean patients (4), the study performed by Liu et al. on Chinese patients (10), and both studies were conducted on 2D-CT images. Furthermore, Hwang et al. reported the averages of the right-left sides without making a distinction between painful and pain-free sides in patients with TN (4).

When Hwang et al. evaluated the FO length and width according to sex in patients with TN, they found that the FO length was $8.24 \mathrm{~mm}$ on the right side and $8.32 \mathrm{~mm}$ on the left side and the FO width was $4.09 \mathrm{~mm}$ on the right side and $4.02 \mathrm{~mm}$ on the left side among males (4). At the same time, they found that the FO length was $7.93 \mathrm{~mm}$ on the right side and $8.13 \mathrm{~mm}$ on the left side and the FO width was 4.16 $\mathrm{mm}$ on the right side and $4.00 \mathrm{~mm}$ on the left side among females. The results obtained by Hwang et al. were slightly different from our results (4). We consider that the reason for this may be that Hwang et al. conducted a study in a different population and on 2D-CT images, and they did not make a distinction between painful and pain-free sides in patients with TN. Hwang et al. also reported no statistically significant difference between the sexes in the FO dimensions (4). Their results are similar to our study.

Cannulation procedures, including procedures using the neuronavigation technology, sometimes become complicated due to anatomical variations of the $F O$, and negative consequences may occur due to incorrect cannulation. Although the FO is generally considered oval-shaped, it has also been reported as "round," "irregular," "almond," "banana," "D-shaped," "pear," and "triangle" (18,19,22). Although variations in the FO shape are normally present, a careful evaluation of this foramen will help neurosurgeons to know the FO shape in approaching the procedures that require the FO cannulation due to its significance in neurosurgical procedures.

When previous studies on the FO shape were compared, it was observed that the FO shape varied considerably between the studies, although the studies other than our study were conducted in the Indian population (Table V). Although the population studied was the same, we considered that the reason for this difference between previous studies might be the difference in the number of samples studied, the unknown factors such as age and sex, and the authors' subjective interpretation of the figures.

In their study conducted on dry skulls, Kumar et al. stated that the FR length and area were $2.9 \mathrm{~mm}$ and $8.82 \mathrm{~mm}^{2}$, respectively, on the right side and $3.29 \mathrm{~mm}$ and $8.61 \mathrm{~mm}^{2}$, respectively, on the left side (9). They also reported no difference in the length and area parameters of the FR according to sides and sex. While the value they found for the FR mean length is similar to that in our study, the mean area is different. This difference may be due to different populations 
Table V: Comparison of the Shapes of the Foramen Ovale in Previous Studies

\begin{tabular}{|c|c|c|c|c|c|c|c|c|c|}
\hline Authors & $\begin{array}{c}\mathbf{n} \\
\text { Population } \\
\end{array}$ & Method & $\begin{array}{c}\text { Round } \\
(\%)\end{array}$ & $\begin{array}{c}\text { Oval } \\
(\%)\end{array}$ & $\begin{array}{c}\text { Irregular } \\
(\%)\end{array}$ & $\begin{array}{c}\text { Pinhole } \\
(\%)\end{array}$ & $\begin{array}{c}\text { Almond } \\
(\%)\end{array}$ & $\begin{array}{c}\text { Kidney } \\
(\%)\end{array}$ & $\begin{array}{l}\text { Slit } \\
(\%)\end{array}$ \\
\hline Tewari et al. (18) & $\frac{68}{\text { Indian }}$ & Skull & 55.56 & 33.33 & 3.96 & 7.14 & - & - & - \\
\hline Somesh et al. (16) & $\frac{82}{\text { Indian }}$ & Skull & 10.97 & 56.7 & 3.65 & - & 28.65 & - & - \\
\hline Khairnar and Bhusari (8) & $\frac{100}{\text { Indian }}$ & Skull & 7 & 76.5 & - & - & 10.5 & - & 6 \\
\hline $\begin{array}{l}\text { Present study } \\
\text { Asymptomatic }\end{array}$ & $\begin{array}{c}316 \\
\text { Turkish }\end{array}$ & 3D-CT & 2.2 & 81 & - & - & 14.9 & 1.9 & - \\
\hline $\begin{array}{l}\text { Present study } \\
\text { Trigeminal neuralgia }\end{array}$ & $\frac{38}{\text { Turkish }}$ & 3D-CT & - & 81.6 & - & - & 18.4 & - & - \\
\hline
\end{tabular}

studied and their measurement of the FR area using a different method (ImageJ program). In our study, the FR dimensions did not exhibit a statistically significant difference between the right and left sides in asymptomatic individuals. When the FR dimensions were compared according to sex, although the length and width parameters were significantly higher in males, no significant difference was found in the area parameter. While the length and width parameters were significantly different between sexes, the fact that the area parameter was not significantly different may be due to the FR shape.

Erbagci et al. investigated the FR dimensions in patients with TN $(n=20)$ and the control group $(n=24)$ (2). They found that the FR mean dimension was $3.04 \times 3.2 \mathrm{~mm}$ on the right side and $2.8 \times 2.9 \mathrm{~mm}$ on the left side in patients with $\mathrm{TN}$. In the control group, they determined that the FR mean dimension was $2.4 \times 3.2 \mathrm{~mm}$ on the right side and $2.5 \times 3.1 \mathrm{~mm}$ on the left side. Their results obtained for the control group are similar to those in our study. However, our results were different from their results for patients with $\mathrm{TN}$. We considered that this difference was caused by the fact that they only gave the averages for the right and left sides in patients with TN, and they did not provide information about the painful and pain-free sides as in our study.

Liu et al. obtained the FR mean diameter to be $2.50 \pm 0.40 \mathrm{~mm}$ on the painful side and $2.71 \pm 0.45 \mathrm{~mm}$ on the pain-free side on the CT images of patients with TN (10). They also found that the FR mean diameter was $2.52 \pm 0.43 \mathrm{~mm}$ on the right side and $2.65 \pm 0.45 \mathrm{~mm}$ on the left side in the same patients with TN. Although the FR mean diameter on the painful side and the right side was narrower than the contralateral side, they could not find a statistically significant difference between the painful and pain-free sides $(p=0.09)$ and between the right and left sides $(p=0.28)$. In the healthy and volunteer groups, the researchers reported the FR mean diameter as $2.68 \pm 0.38 \mathrm{~mm}$ on the right side and $2.56 \pm 0.41 \mathrm{~mm}$ on the left side. They indicated no significant difference between the sides. Similar to their study, our study found no significant difference between the right and left sides in asymptomatic individuals in the FR dimensions. In the comparison between painful and pain-free sides in patients with TN, although the FR dimensions were smaller on the painful side, no statistically significant difference was observed.
Erbagci et al. investigated the FO and FR dimensions on the CT images of patients with TN and healthy volunteers and suggested no relationship between the dimensions of these foramina and TN (2). Contrary to the findings obtained by Erbagci et al., when all parameters related to the $\mathrm{FO}$ and FR in asymptomatic individuals and patients with TN were compared in our study, the length and width of the FO and FR (except for the FO length) were found to be statistically significantly smaller in patients with TN (2). We consider that the statistically significantly smaller length and width of the FO and FR in patients with TN may explain the cause of TN.

The distances of the FO and FR to the $x$ and $y$-axes (except for the FO distance to the $y$-axis) were found to be significantly shorter in patients with TN. We consider that the significantly shorter distance of the FO to the $\mathrm{x}$-axis in patients with TN may be related to the narrower angle of the mandibular nerve while progressing forward after exiting the FO. We think that the fact that the FR distance to the $y$-axis was significantly smaller in both patients with TN and on the painful side in comparison with the pain-free side, in other words, the presence of the FR in the more medial side may be the cause of TN associated with the FR, which can be explained by the fact that the maxillary nerve made a narrower angle towards the anteromedial while entering the FR. However, these ideas just remain as comments. We consider that our study alone is not enough in this regard, and further studies should be conducted.

The sphenoid bone contains numerous foramina providing the extracranial passage of nerves and venous plexuses. The FV is one of these foramina $(9,15)$. The FV connects the pterygoid plexus with the cavernous sinus and transmits a small emissary vein draining the cavernous sinus. The significance of the said channel is based on the fact that it offers a way for the infection to spread from an extracranial source to the cavernous sinus. The FV is a small and inconstant channel. It is located between the FO and FR and anteromedially to the FO in an intracranial view $(7,15)$. Due to the close proximity of the FV with the FO, while treating TN by the radiofrequency rhizotomy method, it can be inserted iatrogenically with a needle placed into the FV by mistake, and serious complications such as intracranial bleeding may occur. Therefore, it is important to 
know the frequency of the FV, and it has been reported in a wide range at varying rates in the literature (15). Williams et al. reported that the FV was sometimes found in dry skulls by $8.5 \%$ (20). Wysocki et al. detected the FV in $17 \%$ of the cases (21). Ramalho et al. (14), and Kaplan et al. (6) indicated the FV presence by $71.87 \%$ and $100 \%$, respectively, which are considerably higher rates. In our study, the FV was found only in asymptomatic individuals by $4.11 \%$ (4 on the right side, 5 on the left side, and 2 bilaterally).

The present research has some limitations. Firstly, the nature of the study was retrospective. Secondly, the technical parameters of CT imaging could not be optimized since the study was retrospective. Thirdly, the number of patients with TN was low.

\section{CONCLUSION}

The fact that the length and width parameters of the FO and FR were statistically significantly different (except for the FO length) in asymptomatic and in patients with TN was an important conclusion of this study. This result also indicates that the narrow FO and FR may be the cause of TN. The relationship of the $\mathrm{FO}$ and $\mathrm{FR}$ localizations with $\mathrm{TN}$, which had not been previously evaluated in the literature, was also mentioned in this study. The fact that the distances of the $\mathrm{FO}$ and FR to the $\mathrm{x}$ and $\mathrm{y}$-axes were significantly different in patients with TN compared to asymptomatic individuals suggested that these parameters might be the cause of TN. However, it is necessary to conduct a comprehensive study on this issue with more TN patients. Furthermore, this study will make a significant contribution to the literature on the knowledge of the dimensions and localizations of the FO and FR in asymptomatic individuals and patients with TN.

\section{REFERENCES}

1. Cheng Y, Yu H, Xu S, Xu H, Zhang S, Mu Q, Li Y, Zhao G: A new method of locating foramen rotundum and its anatomic study. J Craniofac Surg 26:528-531, 2015

2. Erbagci H, Kizilkan N, Sirikci A, Yigiter R, Aksamoglu $\mathrm{M}$ : Computed tomography based measurement of the dimensions of foramen ovale and rotundum in trigeminal neuralgia. Neurosciences 15:101-104, 2010

3. Gupta T, Gupta SK: Original landmarks for intraoperative localization of the foramen ovale: A radio-anatomical study. Surg Radiol Anat 34:767-772, 2012

4. Hwang SH, Lee MK, Park JW, Lee JE, Cho CW, Kim DJ: A morphometric analysis of the foramen ovale and the zygomatic points determined by a computed tomography in patients with idiopathic trigeminal neuralgia. J Korean Neurosurg Soc 38:202-205, 2005

5. Inal M, Muluk NB, Arikan OK, Sahin S: Is there a relationship between optic canal, foramen rotundum, and vidian canal? J Craniofac Surg 26:1382-1388, 2015

6. Kaplan M, Serhat F, Faik M, Topsakal C, Sam B, Tekdemir I: Review of complications due to foramen ovale puncture. J Clin Neurosci 14:563-568, 2007

7. Karthikeyan G, Sankaran PK, Raghunath G, Yuvaraj M, Arathala R: Morphometric study of various foramina in the middle cranial fossa of the human skull. Indian J Clin Anat Physiol 4:574-578, 2017
8. Khairnar KB, Bhusari PA: An anatomical study on the foramen ovale and the foramen spinosum. J Clin Diagnostic Res 7: 427-429, 2013

9. Kumar A, Sehgal R, Roy TS: A morphometric analysis and study of variations of foramina in the floor of the middle cranial fossa. J Anat Soc India 65:143-147, 2016

10. Liu P, Zhong W, Liao C, Liu M, Zhang W: Narrow foramen ovale and rotundum: A role in the etiology of trigeminal neuralgia. $J$ Craniofac Surg 27:2168-2170, 2016

11. Natsis K, Repousi E, Sofidis G, Piagkou M: The osseous structures in the infratemporal fossa: Foramen ovale, bony spurs, ossified ligaments and their contribution to the trigeminal neuralgia. Acta Neurochir (Wien) 157:101-103, 2015

12. Neto HS, Camilli JA, Marques MJ: Trigeminal neuralgia is caused by maxillary and mandibular nerve entrapment: Greater incidence of right-sided facial symptoms is due to the foramen rotundum and foramen ovale being narrower on the right side of the cranium. Med Hypotheses 65:1179-1182, 2005

13. Patil J, Kumar N, Mohandas Rao KG, Swamy Ravindra S, Somayaji SN, Satheesha Nayak B, Marpalli S, Ashwini LS: The foramen ovale morphometry of sphenoid bone in southern indian population. J Clin Diagnostic Res 7:2668-2670, 2013

14. Ramalho A, Sousa-Rodriguez C, Rodas P, Lins C, De Lima R, Almeida E, JABS N: A incidência e as relações morfométricas do forame emissário do esfenóide em crânios humanos. Int J Morphol 25:147, 2007

15. Shinohara A, de Souza Melo C, Silveira E, Lauris J, Andreo $\mathrm{J}$, de Castro Rodrigues A: Incidence, morphology and morphometry of the foramen of Vesalius: Complementary study for a safer planning and execution of the trigeminal rhizotomy technique. Surg Radiol Anat 32:159-164, 2010

16. Somesh MS, Sridevi HB, Prabhu LV, Swamy MSG, Krishnamurthy AK, Murlimanju BV, Chettiar GK: A morphometric study of foramen ovale. Turk Neurosurg 21:378383, 2011

17. Spina A, Nocera G, Boari N, lannaccone S, Mortini P: Efficacy of Gamma Knife radiosurgery in the management of multiple sclerosis-related trigeminal neuralgia: A systematic review and meta-analysis. Neurosurg Rev, 2021(Online ahead of print)

18. Tewari S, Gupta C, Palimar V, Kathur SG: Morphometric analysis of foramen spinosum in South Indian population. Acta Med Iran 56:113-118, 2018

19. White HJ, Reddy V, Mesfin FB: Anatomy, Head and Neck, Foramen Spinosum. In: StatPearls, 2020

20. Williams PL, Bannister LH, Berry MM, Collins P, Dyson M, Dussek JE, Ferguson MW: Gray's Anatomy: The Anatomical Basis of Medicine and Surgery. $38^{\text {th }}$ ed. New York: Churchill Livingston, 1995

21. Wysocki J, Reymond J, Skarżyński H, Wróbel B: The size of selected human skull foramina in relation to skull capacity. Folia Morphol (Warsz) 65:301-308, 2006

22. Zdilla MJ, Fijalkowski KM: The shape of the foramen ovale: A visualization aid for cannulation procedures. J Craniofac Surg 28:548-551, 2017

23. Zhu B, Wang H, Liu M, Cheng K, Li Z, Li Y: Morphologic study of foramen oval region on surgery approach for trigeminal neuralgia. J Craniofac Surg 26:541-543, 2015 